\title{
Reconceptualising organisational collaborations in social science doctoral education
}

\section{David Mills ${ }^{1}$ (D) David James ${ }^{2}$}

Published online: 16 August 2019

(C) The Author(s) 2019

\begin{abstract}
Empirical social science research increasingly involves working collaboratively with organisations beyond the university. This paper contributes to the growing international literature on doctoral collaboration by exploring how UK doctoral students in the social sciences negotiate organisational collaborations. We draw on narrative interviews and administrative data to create a series of case-study vignettes. We juxtapose these with a theorisation of disciplinary knowledge practices to show how such collaborations are at once demanding and unpredictable, but also generative of new understanding and insights. We suggest that Burawoy's (American Sociological Review, 70(1), 4-28, 2005) model of the 'antagonistic interdependence' of public, critical, professional and policy sociologies is helpful as a heuristic for conceptualising doctoral student experiences of a range of different (and often contradictory) forms of social scientific knowledge. Our analysis demonstrates that both instrumental and critical forms of social knowledge can emerge from organisational partnerships and placements. We call for further attention to the 'generative paradoxes' (Bartunek and Rynes Journal of Management, 40(5), 1181-1201, 2014) and 'reflective entanglements' (Jagoda 2016) that result from doctoral collaborations, and for doctoral pedagogies that help students use these experiences to develop criticality and see it as a key skill in social research.
\end{abstract}

Keywords Collaboration · Doctoral education · Criticality $\cdot$ Epistemology $\cdot$ Social sciences

\section{Introduction}

Since the 1980s, conceptual models of a knowledge economy (Bell 1973), powered by evercloser university-industry relations (Gibbons et al. 1994, Etzkowitz and Leydesdorff 1998,

David Mills

david.mills@education.ox.ac.uk

1 Department of Education, University of Oxford, 15 Norham Gardens, Oxford OX2 6PY, UK

2 University of Cardiff, Cardiff CF10 3AT, UK 
Lam 2010), have become increasingly central to national higher education policies. This focus on strong university-industry partnerships, and the anticipated labour market demand for the knowledge and professional skills generated through doctoral study (Enders 2002; Enders and de Weerdt 2004), has led to innovative industrial doctorates and collaborative doctoral programmes.

Learning from models first trialled in Scandinavia in the 1970s (Assbring and Nurr 2017), many European funding schemes now require organisational collaborations to be integrated into doctoral programmes (Thune 2010). In the UK, the Economic and Social Research Council (ESRC) has promoted industrial studentships, organisational placements and collaborative doctoral projects since the 1980s (Demeritt and Lees 2005). Funders of social research promote doctoral collaborations with a range of civil society, commercial and state organisations, seeing these links as contributing to the skills of researchers and facilitating the impact of research beyond the university.

In the social sciences, organisational collaborations offer new opportunities for public engagement and knowledge exchange. They also raise important questions about epistemology, autonomy and critical freedom within doctoral education. Sociologists of higher education have long been critical of creeping corporate influence (Veblen 1957, Slaughter and Rhoades 2004, Chan and Fisher 2008), a normative position that informs Slaughter et al's (2002) analysis of graduate students as 'exchange tokens' trafficked between academia and industry. Within the field of Higher Education, there is a growing evidence-base on industry-doctoral collaborations (e.g. Enders and de Weerdt 2004, Borrell-Damian and European University Association 2009, Thune 2009, 2010, Hancock 2019) but this work tends not to foreground individual student experiences, the pedagogy of partnerships, or the role of collaborations in generating critical reflection and new knowledge.

In this paper, we begin by presenting an overview of the existing literature on doctoral collaborations. Drawing on two years of interview-based research with a range of UK social science doctoral students involved in non-academic collaborations together with our own administrative experience facilitating such collaboration, we develop four illustrative vignettes. These are chosen to offer grounded insight into the very different challenges students face in 'managing' and sustaining these partnerships. They illustrate how learning occurs through tensions, failure and frustration as well as from productive relationships, and that 'critical' insights emerge from the mundanities of organisational engagement.

We then turn to Burawoy's analysis of disciplinary practices and sociological 'labour' (2005) to conceptualise these different collaborative experiences, complementing it with theorisations of collaboration from within the field of organisational studies (Bartunek and Rynes 2014) and new media studies (Jagoda 2016). These analytical models are discussed after the vignettes, and offer a heuristic framework through which to make sense of the students' experiences, and to conceptualise the interdependency of 'instrumental' and 'reflexive' knowledge production. Reflecting on the epistemological challenges of collaborative doctoral research, and acknowledging our own role in training and supporting these doctoral projects, we explore what criticality means for research students working in and across organisational boundaries, how it might be sustained, and why it matters for the future of the social sciences. We suggest that non-academic collaborations, for all their challenges, paradoxes and contradictions, have a vital pedagogic role to play within social science doctoral education. 


\section{The emergence of doctoral collaborations}

Since the 1980s, European public policy has justified higher education research funding as an investment in future 'human capital'. The nadir of this rhetoric was the European Council's 2000 'Lisbon Agenda' with its blueprint for making the EU the 'most competitive and dynamic knowledge-based economy in the world' by 2010. Whilst this vision was subsequently sidelined by the financialisation of European economies and the crash of 2008 (Birch and Mykhenko 2014), the discourse of 'Industry 4.0' (Reischauer 2018) continues to drive the creation of innovation systems that encompass business, academia and politics. Higher Education policy 'imaginators' (Wright 2016) promote user-friendly analytical models of the academia-industry nexus, such as the conceptualisation of 'entrepeneurial science' underpinned by a 'triple helix' innovation system (Etzkowitz and Leydesdorff 1997). In the 'triple helix' model, 'universities, firms and governments assume some of the capabilities of the other, even as each maintains its primary role and distinct identity' (Etzkowitz and Leydesdorff 1997, 2). Despite being criticised for its 'pre-packaged' thinking and its lack of contextual specificity (Shinn 2002), the model, like work theorising the social and economic contributions of 'mode 2' academic knowledge (Gibbons et al. 1994), has strongly influenced policy debate.

Growing EU and UK policy support for non-academic collaborations has allowed universities to diversify funding sources, to develop partnerships and use student researchers to build links (Bell and Read 1998, 6). Pioneering European examplars included Industrial Research Schools in Sweden, CIFRE in France, and Industry $\mathrm{PhD}$ programmes in Norway and Finland (Thune 2010). Salminen-Karlsson and Wallgren $(2008,90)$ describe the deep cooperation that develops between academic and industrial supervisors in the Swedish context, and the role of students as 'boundary subjects', actively negotiating two different institutional cultures. Structured collaborations with non-academic organisations are increasingly embedded within European doctoral training funding. Well-established training programmes, including the $E U$ Marie Sklodowska-Curie networks and Industrial Doctorates, require student researchers to gain experience in organisations. Anticipating labour market demands, universities continue to diversify the 'organizational and structural forms' of doctoral training and the range of 'validation criteria' they employ (Enders 2005, 119, Enders and de Weerdt 2004, Gemme and Gingras 2008). The 'overproduction' of doctorates relative to academic positions (Bloch et al. 2015) also drives concerns to ensure the 'transferability' of expertise, and the provision of graduates with generic 'employability' skills (Barnacle and Dall' Alba 2011).

'Evidence' on the efficacy of university-industry collaborations is often policy-led. In the 2000s, the first of a suite of three UK government reviews and reports on business-university collaborations HM Treasure (2003) (Lambert Review) called for research to be more closely harnessed to the goals of national competitiveness, regional economic development and local regeneration. The next, the Wilson Review (BIS 2012) on business-university links, criticised universities for their 'lack of engagement with employers', the deficit of 'enterprise skills required by business' and the disappointing 'level of preparation for $\mathrm{PhD}$ students outside academe'. By contrast, CASE awards were portrayed as a success story, and the Wilson review recommended more emphasis on 'enterprise skills and business experience', and internships for all $\mathrm{PhD}$ students. The third and most recent reprise of this discourse, the Dowling Review (2015), proposed ways to boost 'strategic research partnerships' between business and university. Acknowledging (as if it need to be said) that 'people are central to successful collaboration,' the Review called for research students to form 'connections with business at 
the outset of an academic career path', to 'spend time in business as part of their doctoral training' and for universities to facilitate industrial placements $(2015,5)$, and recommended funding CASE partnerships with SMEs. The Dowling review continued to frame both universities and students as constraining factors, with students seen to lack the necessary business skills, even despite the acknowledgement that they sometimes initiate and drive nonacademic research collaborations. In the UK, the 2017 Industrial Strategy embedded these new policy discourses through a major injection of priority-led research funding.

One challenge for scholars is that national funding and research policy agendas are evanescent and evolving. The policy discourse around 'knowledge exchange' and 'collaboration', especially within the UK social sciences, evokes egalitarian partnerships, mutual benefit and generative insights. Research-industry 'partnerships' have a rather different meaning in the life sciences, driven by commercial concerns and IP issues. The latter involves pre-defined research problems; the former are more emergent and organic. Given this diversity, each type of collaboration requires different forms of training and preparation for students. Given the potential of doctoral collaborations to generate what Thune calls 'diverse sources of innovation' (2010), a narrow focus on training 'triple helix workers' risks promoting instrumentalism rather than the search for new knowledge.

Most UK research councils promote collaborative studentships, portraying them as a means for 'enhancing student development' (AHRC), 'increasing employability' (NERC) and 'seeing how research skills and outcomes apply in organisations' (ESRC). In the social sciences, 'Knowledge Exchange' is the policy glue that seeks to hold these different agendas together, defined as a 'two-way process where social scientists and individuals or organisations share learning, ideas and experiences' (ESRC). The aim is to help both sides 'learn about each other's expertise (and) professional cultures' (ESRC). This is potentially a call to democratize knowledge generation, going beyond the encounter between different forms of expertise to the collaborative co-creation of new knowledge. And in the ESRC's purview, 'collaborations' are not between individuals but between 'researchers' and 'the private, public and civil society sectors' (ESRC website). To meet this policy challenge, the ESRC has broadened its understanding of doctoral collaborations to include a whole range of activities, from short internships to full studentships, though an expectation of 'substantial non-academic user engagement' is left undefined, alongside exhortations that 'genuine collaboration engages non-academic partners in the research process from day one'.

In the UK, the first 25 CASE (Collaborative awards in Science and Technology) social science research studentships were funded in 1994. Initial sponsors included companies such as Unilever and Mars, as well as charities, banks and government departments. With this sudden injection of funding, the Economic and Social Research research council found itself struggling to meet its target of 125 'CASE' studentships/year by 2000. Between 2000 and 2005, the ESRC awarded around 65 such studentship awards each year to 56 higher education institutions (HEIs) in England, Scotland and Wales, making up $9 \%$ of all social science studentship awards. Despite the marked regional disparities in these awards, Demeritt and Lee argue that the 'collaborative awards scheme linking academic and non-academic partners in the training of $\mathrm{PhD}$ students' is crucial to ensuring 'that future social scientists...have the skills to work in a non-academic as well as an academic environment' $(2004,1)$. The Council continued to prioritise these awards, and the proportion of CASE awards increased to more than $11 \%$ in 2007. A new ESRC doctoral training network in 2010 saw funding devolved to 22 university-based Doctoral 
Training Centres, each of which were expected to ensure that at least $20 \%$ of their doctoral students were involved in some form of non-academic collaboration. ${ }^{1}$

The research evidence on the impact of doctoral collaborations comes primarily from science-industry collaborations but also offers insights for the social sciences. A major European survey of industry-university doctoral collaborations (Borrell-Damian et al. 2010) highlights the wide diversity in types of institutional involvement, approaches to coursework and placements, models of partnership governance (including IP agreements), and genres of research and supervision. Thune's (2010) interviewees describe how successful institutional partnerships work best with knowledge-intensive industries who have a history of academic engagement.

There is contradictory evidence on how doctoral collaborations with industry shape postdoctoral employment trajectories. Evidence from scientific fields with mature patterns of common training and 'socialisation' points to the positive benefits of these links for what Thune (2010) calls 'future 'triple helix workers". In some science fields, organisational collaboration is now a normalized practice. Gemme and Gingras (2012) suggest, on the other hand, that academic positions continue to dominate the 'professional dreams' of early career researchers. This tension is explored in Lam's study of the strategic entrepreneurialism and institutional 'boundary work' deployed by UK scientists. Lam (2010) shows how researchers develop tactically hybrid identities, skilfully exploiting the professional ambiguities and possibilities generated at the academic-industry interface. Aware of their breadth of expertise, the doctoral scientists interviewed by Hancock (2019) rejected the academic 'game' in favour of a career in industry. Hancock uses the principles of game theory to analyse what he suggests are the different 'ideal-type' strategies adopted by doctoral scientists in relation to the knowledge economy, from 'scientific purists' and 'social idealists' through to 'pragmatists' and 'third-order' capitalists. Gu et al. (2018) provide evidence that Chinese students want to be trained as 'versatile experts' as well as 'academic successors', whilst Etmanski's (2019) large scale survey of US doctoral programmes questioned 'binary' models of scientific career aspirations as either targeted towards, or away from, academia. Collectively, this work offers a nuanced and complex picture of contemporary science practices, attitudes and careers. A similar mapping is emerging in the social sciences (McAlpine and Amundsen 2019).

Work by Salminen-Karlsson and Wallgren (2008), Kitigawa (2014) and Hancock (2019) foregrounds the role that research students play in building these partnerships. Supervisory expertise is also key. Thune (2010) argues that supervisory experience, the size of the research organisation, and the partner's commitment to the project, are key variables shaping the student experience. Amidst the growth of 'strategic engagement' by companies with universities, and the largely positive views of participants, this work also acknowledges 'compromises in selecting and fixing the research topic, leaving no party entirely satisfied', 'conflicts over publication rights' and 'limited freedom for the development of break-through ideas' (Borrell-Damian et al. 2010, 23). Concerns usually revolve around IPR disputes, communication misunderstandings or delays to completion.

Unlike academic surveys and studies of scientific career strategies (Lam 2010, Etmanski 2019, Hancock 2019), policy evaluations tend not to ask the more fundamental questions about epistemology, criticality and independence generated by organisational collaborations. Calhoun and Rhoten (2010) highlight the role of interdisciplinarity in generating disciplinary

\footnotetext{
${ }^{1}$ A second round of ESRC funding, consolidating 22 Doctoral Training Centres into 14 Doctoral Training Partnerships (DTPs) has seen this collaboration target rise from 20 to $30 \%$. The target is likely to increase.
} 
insight, whilst Brodin (2016) underscores the value of cultivating 'critical creativity' within doctoral supervision in ways that foster independence but avoid disciplinary defensiveness. Our own interest in the potential for sustaining research criticality whilst developing organisational partnerships motivated this research project on doctoral student collaboration.

\section{Research methods}

Social science students collaborate with non-academic organisations in a range of ways. Our motivation to explore this topic - and our analysis - grows from our combined administrative experience of two decades of leading social science doctoral training programmes, including the facilitation of collaborative studentships and other forms of collaboration. ${ }^{2}$ Over the last two years, we have begun to conduct semi-structured narrative interviews with research students collaborating with companies, charities, government agencies and NGOs, exploring their experiences of initiating, managing and negotiating such arrangements. To date, we have completed 10 interviews with current - and recently completed - social science doctoral students whose studies have included a strong element of intended and/or manifest collaboration. This paper draws upon our analysis of this material and on our own administrative experience and data on organisational collaborations.

In the UK, the non-academic organisational funding, support and commitment to collaborative doctoral research in the social sciences vary widely. Some projects are formally cofunded and involve written legal agreements; others revolve around 'in-kind' resources or mentoring commitments, whilst a few emerge informally from researchers' own acts of reciprocity and 'knowledge exchange'. Some collaborations are related to, or augment, a larger research collaboration, whilst others are free-standing. Most are with NGOs or governmental agencies, and relatively fewer with companies. Each presents its own challenges, as our case-studies reveal.

Initially we expected that there would be some utility in classifying doctoral collaborations in terms of their origins, such as the source of the original idea (e.g. organisation/supervisor/ student), or whether or not co-funding was involved, and so forth. However, such typologies began to crumble as soon as we began to analyse our interview and administrative data. Each collaboration has its own history and specificity. Some are pre-planned and tightly defined by a supervisory team in conjunction with a project 'partner'. Others emerge serendipitously during the course of fieldwork. Occasionally, the students do not even conceive of their research design as having a collaborative dimension: they start out seeking access to an organisation in order to do fieldwork or utilise administrative data; then, a more meaningful partnership or 'two-way' collaboration develops over time. Where these emerge organically, doctoral students are often relatively unaware of the negotiating and teamworking skills they are developing to sustain these relationships. Semi-structured narrative interviews provide space for autobiographical reflections on practice, as well as time to dwell on the challenges - practical as well as epistemological - that doctoral collaborations present. They are commonplace within the qualitative social sciences (Riessman 2008), and the approach has been used to good effect by researchers studying the identity 'trajectories' of early career researchers (McAlpine and Amundsen 2017; Chen et al. 2015).

\footnotetext{
${ }^{2}$ The most significant part of this experience is that we both directed ESRC Doctoral Training Centres and Doctoral Training Partnerships from 2011 to 2019.
} 
Findings Narrative and biographical methods generate rich insight into individual lives and experiences. From our interview narratives, we developed four case-study 'vignettes' that exemplify the different phases of doctoral collaboration that emerged during the interviews. Each vignette is based on an individual case. Every student we interviewed described a practical or epistemological challenge.

The vignettes have been chosen to illustrate the diversity of organisational attitudes and bureaucratic practices that our student participants encountered. Whilst each is based on one of our early interviewees, there is already strong resonance with the experiences of other students in our research. The first describes a student's struggle to get an informal agreement formalised in writing by an organisation in order to secure research council funding. The second vignette is based on the experience of a supervisor-initiated collaboration agreement that had no real substance in terms of organisational commitment, leaving the student adrift and lacking in guidance. In the third, an initial agreement brokered by a supervisor had to be given meaning and focus by a student. She struggled to secure the support and research data she needed, but did not want to risk damaging the personal relationship between the supervisor and the contact. The fourth describes a 'stalled' collaboration and the significance of its early abandonment. The students have all been given pseudonyms, and any identifying features have been changed.

Together, the vignettes illustrate the different risks facing students and supervisors, and the learning that comes from managing the collaborative relationship itself. The vignettes exemplify the challenges of brokering collaboration, the different roles that supervisors can play and the complexities of collaborative working. In each case, the student (and supervisor) has to work with the demands of professional and commercial organisations (including control over access, data and knowledge), a process that produces critical insights into these organisational dynamics. However, here we wish to focus on what is revealed about epistemological and disciplinary tensions created by collaborative doctoral projects, and we return to this point after the four vignettes.

\section{Vignette 1: On negotiating access and protecting autonomy}

With a background in accountancy, Daniel spent six months trying to design a doctoral research project with one or more corporate partners in the financial sector. His ambition was to secure an ESRC 'collaborative' studentship working with a commercial organisation, funded by the UK's National Productivity Investment Fund. His proposed project, looking into how companies reported on their corporate social responsibility roles, faced the bureaucratic challenge of meeting strict funder expectations about a written collaboration commitment. Daniel worked tirelessly, and to tight deadlines, to secure the necessary commitments and a written statement of intent. This involved repeated phone calls, meetings and conversations, and having to quickly develop an understanding of the internal dynamics and constraints on employees.

Daniel's challenge was made more acute in that he was applying for a doctoral studentship during his Masters' degree, and so did not hold an existing institutional affiliation as a research student. With no pre-existing research partnership or supervisory connections to rely on, the challenge ultimately proved just too difficult. In conversation, he talked reflectively about the demands of nurturing a supportive network of potential non-academic collaborators tactfully and diplomatically, and the difficulty of turning this into a written agreement.

Daniel described how he gradually built his network and developed trust through conversations with a range of individuals within these firms, who then 'passed him on' to others in 
more senior roles. It became clear that it would take much longer than originally planned, partly because of the commercial sensitivities that surrounded the project, but also because of an unwillingness of individuals to turn their own commitment into a formal agreement. On the one hand, the funding body required written evidence of a 'confirmed' non-academic collaboration, but his financial sector partners were reluctant to create formal obligations. For them commitment emerged through the slow process of building trust. One of his fellow students had spent eighteen months gaining sufficient access to senior professionals within a law firm.

Reflecting on the larger collaboration agenda, Daniel emphasised the risks of becoming 'over-engaged', saying that this would potentially limit 'one's ability to be critical'. He felt that this would not be in the interest of the company either, except for those actors who simply wanted the researcher to endorse their own practices. Whilst accepting that links between universities and industry are 'a reality' and 'politically desirable', Daniel was articulate in defending the role of 'departmental structures' and doctoral programme requirements in sustaining space for critical research and agency.

Daniel was clear that the university had a role to 'help buffer students against the demands' of commercial organisations, ensuring that students are 'less exposed...to non-academic demands to certify your competency'. More broadly, he was sceptical of the expectations created by the 'impact agenda', feeling that it was an unclear and 'empty concept', that those who defined impact were also able to determine research outcomes, a process he felt threatened the 'freedom of science'. Reflecting on the temporality of the university, he commented that 'researchers do not see the value of impact measurement because it allocates energy towards short-term goals'.

Daniel remained committed to developing partnerships during the course of his doctoral research, and later became involved in a small 'start-up' technology company. However, he recognised that research and research outcomes were understood differently by those working in commercial-sector organisations. Reflecting on what he called the 'paradox of academicindustry collaboration', Daniel pointed out that practitioners 'prioritise the norm and logic of their industry in their understandings of research evidence' whilst academics prioritise the logic of their research discipline. This leads each group to emphasise different aspects of the research process. He felt it was incumbent on students to understand and negotiate these differences. As he put it, "practitioners assume researchers are consultants...and they are valuable because they hold knowledge. Practitioners have to see the purpose of an action, but in research you do not know what the outcome is'.

\section{Vignette 2: On translating research and managing identities}

Having completed a taught Master's degree in Criminology, Sophie had worked for several different charities. It was whilst looking for a new job that she came across an advertisement for a collaborative $\mathrm{PhD}$ studentship, jointly funded by a university and a charity concerned with both practice and policy in the criminal justice system. She applied and was successful. The doctoral project was to be jointly supervised by staff from both organisations, and the student would be based for two days per week in the charity.

The studentship commenced mid-year, which meant that Sophie did not find herself 'in sync' with other doctoral students, all of whom had started in September. With the exception of two early supervision meetings that included some re-negotiation of the core purposes of the research, there were no meetings with both supervisors together, and the planned regular and formal involvement of the charity in supervision did not transpire. The collaboration was more 
imagined than real. Seemingly falling between two stools, Sophie found there was very little individual supervision of any sort throughout the first year, with most support coming from a generic group setting. This unexpected pattern of activity left Sophie feeling disappointed and 'somewhat short-changed'.

Unexpectedly, Sophie's work in the charity brought her into contact with another external research project, led by a rival university. This had a major - if serendipitous - positive influence. It helped her refine her own doctoral study to align with this new project, and strengthened her confidence to pursue it. Nevertheless, aspects of the collaborative arrangement had been, and remained, very difficult to manage. Sophie described how 'negotiating different identities has been a really big part of this $\mathrm{PhD}$ process. Third sector research and academic research are different, and the two speak different languages...I have become a translator across this divide. They (the charity) want mechanisms, they want to know which inputs give which outputs, but everything I do presents them with more complexity'. Sophie says she has learnt to 'stand her ground' and there are times when she finds herself 'opposed to the party line', by which she means the charity's collective view of itself. The benefits to the charity include the application of some of the outcomes of Sophie's doctoral research to their work, and a raised awareness of how research ethics questions are handled in the particular field of work.

Sophie feels that this constant negotiation has both advantages and disadvantages. On the one hand, she has developed and demonstrated her capacity to work across boundaries and to communicate with a range of audiences (including via a blog and through the preparation of policy documents). She has found she can 'switch between identities' and epistemological positions. From her perspective, these skills and experiences position her well to develop a career in either the charity or academic sector (or both). On the other hand, she feels that, apart from the creation of the original opportunity, she has had little help or support in managing the difficult but necessary straddling of these very different research environments. The success of her own project relied heavily on luck: the chance encounter she had with a different collaborative research project involved with this organisation.

\section{Vignette 3: Managing unpredictability, sustaining access}

Harriet came to doctoral study as a mature student with a range of policy research and project management experience, including partnership work with commercial sector organisations in co-designing publishing projects. This had made her cognisant of the need for, as she put it, 'clarity and regular communications to ward against misunderstandings and manage expectations'. Her CV made her the strongest candidate for a collaborative doctoral studentship organised by two academic supervisors in two different departments, working in conjunction with an NGO supporting creative writers. Managing both different disciplinary perspectives and the challenges of collaboration, her project involved a survey of these writers and their views on intellectual property. Other than a brief written agreement with the organisation to fund half the costs of her studentship, there was no pre-defined project or contract, and it was up to her to negotiate the shape of this interdisciplinary research project. She was happy with this understanding and quickly set to work, supported by two supervisors. Despite an initially enthusiastic reception by the organisation to her research pitch, things gradually began to go wrong. The NGO failed to keep its side of the agreement to share its mailing database, partly, Harriet felt, because of a misinterpretation of data protection rules.

What initially appeared to be an organisational blockage turned out to be the consequence of individual power relations. Harriet described how the NGO research director seemed 
threatened by her project, and it took more than six months before colleagues could persuade the director to change his mind. Harriet ended up using her invitation to the NGO's summer party to 'lean on' people and persuade them to give her the database contact details she needed. Describing herself as 'very clear and explicit in my project management style, and committed to timelines', she found herself six months behind schedule, a situation made worse by a poor response rate to her initial emails. The situation caused considerable anxiety. She had planned to develop a number of policy and practice recommendations in collaboration with the organisation, but time pressure made this impossible, as she had to prioritise her own analysis and writing. Regularly reporting on the issue in supervision and keeping a detailed paper trail, she acknowledged that her supervisor was 'too nice' and possibly did not want to risk his own working relationship with the organisation. An interdisciplinary project made this no easier.

Reflecting on the whole experience, Harriet pointed out that there were 'no consequences for the partner organisation if they obstruct the progress of the project, whether deliberately or not'. With few meaningful sanctions she or her supervisor could apply, she had to bear the costs - financial, emotional and logistical - herself. Even with, as she put it, 'nerves of steel', and proven workplace skills, the personal politics and project slippage proved demanding and stressful, and she ended up having to request an extension to her scholarship to avoid going into debt. She developed her own critique of the university. In retrospect, she wished that she had 'got a collaboration agreement in writing, as both sides needed to be clear about the rules of engagement'. Successfully building links with other organisations in the creative sector over the course of her doctorate, she questioned whether her host university was sufficiently committed to 'meaningful, actual' knowledge exchange, and criticised its lack of strategic attention to this vital area.

\section{Vignette 4: On deciding to abandon a collaboration agreement}

Michael's studentship was conceived, in outline, by a doctoral supervisor working with the CEO of a national organisation with extensive responsibilities for educational curriculum and assessment. The broad expectations were documented in a written agreement. At the outset, all parties expected that the study would rely heavily on detailed data held by the organisation, and indeed, this aspect was at the heart of the envisaged originality of the research and its attractiveness as a funded studentship. The organisation made a substantial financial contribution of around a quarter of the total cost of the studentship.

Michael's first six months proved unexpectedly difficult. Whilst the CEO remained committed to the original agreement, it soon became apparent that other staff in the organisation were uncomfortable with fostering access to data, seemingly perceiving it as a form of unnecessary and unwelcome external scrutiny of their work. Michael and his supervisors tried to reassure the individuals concerned about the established standards of ethical research behaviour to which they were working. They also tried to reiterate the terms of the agreement, but all to no avail. Six months in to a 3-year full-time studentship, Michael felt that his project had collapsed, and that even though he had in some ways been productive and busy, that he had wasted a great deal of precious time. He also felt it must somehow be his own fault, and his mood and motivation both became very low.

Michael credited his academic supervisors with helping him to overcome this impasse. Firstly, the supervisors gave him the confidence to 'break with' the written agreement, arguing that further attempts to honour it would be a waste of taxpayer's money. Then in a short series of very frequent meetings, the research questions and fundamental aspects of method were 
revised, and a different theoretical perspective, already familiar to Michael, was adopted to inform the analysis. Michael gained his $\mathrm{PhD}$ without having to extend his registration. In retrospect, he felt that whilst it was a very difficult experience, he learnt a great deal from his experience of 'stalled' collaboration. In particular, he distinguishes between an independent and critical role for research to 'serve everyone', and what he calls the 'narrower requirements' of organisations like the one he attempted to work with. With hindsight, he also now feels - as do his supervisors - that he acted in good faith and that it could have happened to anyone.

These four vignettes encapsulate some important epistemological tensions. For example, in the first, the student (Daniel) works hard to generate a new collaborative studentship. The attempt founders because his 'bottom up' approach to building trust does not furnish a signed contractual agreement in time to guarantee a collaborative studentship. Nevertheless, the experience contributes to a sophisticated understanding of collaboration, and Daniel remains strongly committed to (and involved in) the principle of partnership working. He is articulate about the 'paradoxical' expectations on researchers and practitioners when it comes to the knowledge generated in or derived from research. In the second vignette, a fully formulated collaborative doctorate is advertised with a clear research programme. Yet this fails to become manifest in all but the narrowest sense. Despite this, Sophie's $\mathrm{PhD}$ study becomes very strongly collaborative when she forges a new connection with a different research project which happens to be running in a setting where the organisation is working. In turn, this new collaboration gives rise to difficulties and dissonances ('negotiating different identities' and becoming 'a translator across the divide') which, as in the case of Daniel, are fundamentally epistemological. Sophie recognises this and the value of the skills and capacities she has had to develop to cope, though she also notes how she has had to do so unexpectedly and without support.

Both the third and fourth vignettes speak of difficulties that can arise when different parts of an organisation react in unpredictable ways to a collaborative arrangement. Harriet has a promising relationship with staff 'lower down' but finds a CEO's lack of responsiveness creates delays and ultimately, considerable emotional and financial costs. Meanwhile, Michael's doctorate exists because the CEO of the organisation is enthusiastic about what independent research might bring to the organisation. Yet this commitment (formalised in a written agreement and including a financial contribution) is patently insufficient: staff 'lower down' resists the arrangement and it fails, again resulting in considerable frustration and stress. At first sight, the issues here appear to be about communication (or the lack of it). Yet they also stem from differences in views of what social science research is for, what kind of knowledge it generates and what consequences it may have. It would be naïve to expect different individuals in any given organisation to share one position on these questions.

Articulating these tensions leads to a better understanding of the constraints and affordances of organisational collaborations and what they can offer the next generation of social scientists as part of their doctoral education. Our view is that the examples in our vignettes demonstrate the need for a more careful conceptualisation of the relationship between different genres of disciplinary knowledge production, and in particular the demands of professional and policy knowledge.

\section{Analysis: understanding 'antagonistic interdependence'}

In order to conceptualise and make sense of the epistemological tensions which appear to run through the accounts of the students we have interviewed, and to explore whether such antagonisms and divided loyalties are intrinsic to collaborative doctoral projects, we turn to 
Burawoy's (2005) model of sociological labour. His influential mapping of US sociology sought to explore the consequences of what he called 'the widening gap between the sociological ethos and the world we study' $(2005,263)$. It mapped out the existing 'division of sociological labour' in order to address two key questions: 'knowledge for whom?' and 'knowledge for what?' (ibid, 269).

Burawoy divided his discipline's knowledge practices into a quadrant of four ideal-types, invoking the Frankfurt school dichotomy of 'instrumental knowledge' and 'reflexive knowledge', and a distinction between 'academic' and 'extra-academic' audiences, set out in Table 1 below. Of the four ideal types, professional sociology and policy sociology are associated, Burawoy suggests, with instrumental knowledge - including problem-solving - and the second two with reflexive knowledge, and broader debates about societal values.

Burawoy is explicit about the contradictions within and between each disciplinary quadrant of his model. Our vignettes similarly demonstrate the tension between organisational sensitivities around valuable (instrumental) knowledge and the requirements of the $\mathrm{PhD}$ to contribute new insights and professional knowledge to disciplinary debates. The students encountered rather different understandings and approaches to 'useful' knowledge creation. Burawoy argues that there is an 'antagonistic interdependence' (ibid 259) between different forms of disciplinary knowledge, but that the synergies are threatened by asymmetries of power, in which the instrumental knowledges generated by professional and policy sociology dominate the reflexive knowledges of critical and public sociology. Burawoy's analysis of sociology's division of labour pays close attention to the strengths and pathologies of academic practice, and the political economy of university labour, including the exploitation of part-time and contingent faculty.

Importantly, Burawoy offers examples of individual sociologists being in more than one camp at one time, or making transitions between such camps in the course of a career. Yet he is also frank about the difficulties of making sustained connections across the four sociologies, because 'they call for profoundly different cognitive practices, different along many dimensions - forms of knowledge, truth, legitimacy, accountability, and politics'. He goes further, suggesting that this can lead each domain to have its 'own distinctive pathology'; his list is long and includes insularity, irrelevance, 'methodism', dogma, policy capture by funders and clients, compromise, complicity and intellectual vanguardism. Crucially, rather than attempting to adjudicate on these internal disputes, Burawoy insists on the 'necessary interdependence of (our) divergent knowledges' and the importance of making these different domains 'mutually accountable'.

The generative tensions between different genres of sociological knowledge drive Burawoy's argument. For Burawoy, 'the social sciences are at the crossroads of the humanities and the natural sciences since in their very definition they partake in both instrumental and reflective knowledge' (ibid, p. 286). Whilst the balance and expression of this combination varies from one social science discipline to another (as he goes on to illustrate), the combination itself is key. Instrumental knowledge cannot develop without challenges from reflexive knowledges and values that are drawn from and recharged by the wider society. Burawoy

Table 1 Division of sociological labour (from Burawoy 2005)

\begin{tabular}{|c|c|c|}
\hline & Academic audience & Extra-academic audience \\
\hline Instrumental knowledge & Professional & Policy \\
\hline Reflexive knowledge & Critical & Public \\
\hline
\end{tabular}


(2005) describes the 'organic solidarity' through which each type of sociology 'derives energy, meaning and imagination' (ibid, 288) from its agonistic connections with others. We would argue that the students we interviewed were at once frustrated and stimulated by these agonistic approaches to knowledge production.

Burawoy's intervention provoked intense debate, comparable to those generated by C. Wright Mills' defence of the sociological imagination fifty years earlier (Mills 1959). At a time of sociological anxiety about the university's responsibility to its many publics, and concerns about democratizing sociological knowledge, his call resonated widely. Significant elements of it continue to resonate: three recent edited collections (Nichols 2007, Nyden et al. 2012, Jeffries 2009) have Public Sociology in the title, alongside many online articles and social media posts.

Recent research within organisational studies draws attention to similar distinctions and mutual dependencies. Bartunek and Rynes's (2014) description of the 'generative paradoxes' that define academic-practitioner relationships attends to the epistemological possibilities that emerge from these contradictory roles and identities. Praising the pedagogic abilities of 'intellectual shamans' to hold these paradoxes and oppositions in tension, Waddock (2017) admires organisational scholars such as Karl Weick. Bartunek and Rynes $(2014,1182)$ suggest that the tensions and gaps between academics and practitioners should be treated 'as fundamentally important..for scholarly research and theorizing', rather than as problems to be resolved. Research students may find a way to negotiate these 'generative paradoxes' themselves, but their supervisors and their non-academic collaborators also have key roles to play in this learning journey.

Inevitably, Burawoy's intervention generated a great deal of criticism. The model's heuristic appeal was also seen as its key weakness. Reviewers opined that the framework was too political (Holmwood 2007), too populist (Calhoun 2005) and too typological (Stacey 2007). Gans (2010) wryly noted that the intervention generated more talk about public sociology than practical measures to advance it. Fatsis (2014) suggested that the manifesto, once again, reinforced sociological insularity rather than breaking down the barriers between the university and non-academic organisations. Whilst Burawoy recognises that 'in its origins, sociology was inherently public' (Burawoy 2005, 265), Fatsis argued that Burawoy largely overlooks the rich history of sociological knowledge created beyond the academy.

Despite the criticisms, Burawoy's matrix still offers an invaluable, if somewhat internalist, mapping of the generative contradictions that structure the academic social sciences. His attention to public engagement and policy 'impact' now seems prescient, even if these terms are regularly appropriated by research funders and research quality assessment regimes.

Burawoy's argument that 'the life of the sociologist is propelled by the mismatch of her or his sociological habitus and the structure of the disciplinary field as a whole' (ibid, 272) leads into a trenchant commentary on the 'regimentation' of academic careers. He disparages the length and state of graduate education, questions the focus on mastery of 'abstruse texts' and 'abstract techniques', and bemoans education's ability to 'winnow away' moral commitments.

Burawoy's analysis of the pathologies of disciplinary knowledge practices is not accompanied by strategies for institutional change or pedagogic reform. He recognises that undergraduate students are a key disciplinary public, and that service learning - the combination of community service with instruction and reflection - is a vital disciplinary pedagogy, but does not make the connection to graduate internships and placements. He offers few alternatives to the dominant professional model of graduate education, other than encouraging research students to get involved in public sociology. 
It has been left to others to make the case for new and innovative approaches to graduate education (Gans 2010, Stacey 2007). Gans (2010) calls for structural reforms of doctoral programmes, and proposes 'separate tracks in the curriculum for public sociology' (ibid 123). But specialization and separation is not what Burawoy envisaged. His model provides a powerful pedagogic justification for doctoral education that seeks to engineer those 'difficult connections' between instrumental and reflexive knowledge. If these connections are, as Burawoy argues, constitutive of social science, they are fundamental to the training of social researchers. Yet how do we make the most of the learning that these antagonisms generate? Our argument is that organisational research collaborations, increasingly prevalent across the social sciences, should be designed into doctoral education, along with shared and explicit opportunities for learning from them.

\section{Discussion: towards a three-dimensional view of collaboration}

Our research on non-academic collaboration suggests that the challenges faced by research students working with non-academic organisations are not neatly defined by the type of collaboration in which they are involved. Whilst some collaborations, such as those in vignettes 2, 3 and 4 above, start with clear organisational agreements and legal contracts, the tensions created by uncertainty over access, methods, purpose, data and timing are shared by all, and are perhaps an inevitable aspect of collaborative research, whether pre-defined or emergent. A more meaningful categorization of collaboration attends to the understandings of the forms of knowledge (instrumental, reflective, critical) created on both sides during the course of the collaboration. In each of our vignettes, (including the first, where no formal collaboration was possible) a range of insights (reflective, critical and instrumental) emerged over time. This leads us to develop an epistemology of collaboration that can be mapped onto Burawoy's matrix of sociological knowledge production. To this end, we suggest a threefold classification of collaborations, based on the 'dimensionality' of knowledge, ${ }^{3}$ as we now explain.

A one-dimensional view of collaboration tends to adopt a utilitarian, and sometimes 'deficit' conceptualisation of universities, researchers, supervisors, academic disciplines and students. In this framing, to use Burawoy's language, the organisational 'benefit' is one way and unidirectional. The doctoral researcher gains professional or policy knowledge, understanding and skills through their exposure to a non-academic organisation (whether through a placement or a collaborative research project). The goal is to make the student more 'employable' or to contribute more effectively to a knowledge economy. The pedagogic focus is solely on the student. The policy literature on university-industry collaboration, as well as academic models of the 'triple-helix worker' (Thune 2010), tend to perpetuate a one-dimensional understanding of collaboration. This instrumental view of knowledge is visible in our vignettes (e.g. in a reluctance to share data, or to offer time to the student).

A two-dimensional view adds depth to this one-dimensional view to include a level of reflexive knowledge exchange. The purpose of collaboration now gets understood as facilitating meaningful two-way dialogue and exchange of professional or policy expertise between two or more partners. This vision was clearly behind the initial decisions of the organisations to set up doctoral collaborations, if not always followed through. In principle the student researcher learns from the organisation and vice-versa, with the organisation benefitting from

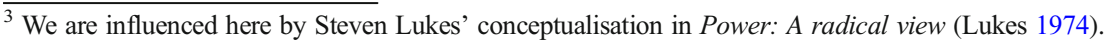


research evidence and alternative conceptual perspectives. The organisation may make explicit use of the doctoral researcher's capacities to prompt reflection or debate, organisational learning, and even changes to its processes, systems or services. The focus here is on mutual benefit, and on mutual learning, even if the epistemological rationale remains largely instrumentalist, to use Burawoy's language.

The full relational potential of doctoral collaboration requires explicit attention to a third dimension. This is where the practices of partnering and collaborating become the focus of reflexive and critical attention by the doctoral researcher, their supervisor and their peers. The student is helped to understand the fraught and antagonistic relationships between public, professional, policy and critical social science knowledges. Each collaboration can be used to exemplify these wider antagonisms, in both its positive ramifications and the struggles to which it gives rise. These can include the difficulties of managing a relationship over time or the tensions between critical researcher independence and the commercial priorities of, say, a for-profit organisation. In this view, collaboration plays an invaluable role in the student's learning. This 'meta' dimension acknowledges that collaborations are always emergent. They develop, fragment or dissipate in unpredictable and serendipitous ways. They require time and energy, are rarely 'fixed' and often highly dynamic. Productive collaboration therefore needs preparatory work, careful monitoring and reflexive attention if its benefits are to be fully realized. Whilst the key beneficiary from this journey is usually the doctoral researcher, as they develop their awareness of the tension between instrumental and reflexive knowledge, this shared learning also benefits the 'non-academic' organisation. This new dimension of doctoral education prepares students well for a range of possible futures, making more fluid transitions between the various 'camps' that they are likely to encounter.

The challenge for educators is to design doctoral pedagogies that combine these three dimensions for best effect, helping students negotiate the 'insider-outsider' dilemmas of collaborative working, whilst also learning how to negotiate antagonistic domains of disciplinary knowledge. Burawoy's matrix mapping of sociological labour shows how social science research journeys can take a myriad of forms - there is no one 'right' place within the matrix to start or finish a research project. For example, an empirical study of school governance could start with an instrumentalist 'policy' goal to improve the effectiveness of local democracy, but end up developing a sophisticated critique of the regulatory arrangements and their framing of the opportunities for community involvement. Or it could become a valuable piece of public sociology, involving parents and other community groups in aspects of governance reform. On the other hand, a doctoral study motivated by theoretical debates might begin as a critical ethnography of a development NGO but end up generating professional and policy recommendations.

How does one help students see that they will benefit from an exposure to all four quadrants of disciplinary practice, given the antagonisms Burawoy outlines? Criticality suggests distancing, autonomy and detachment, whilst collaboration invokes commitment, engagement and participation (Macfarlane 2017). In response, it may be helpful to also think about collaboration as a virtue and practice rather than solely as an organisational process of bridging boundaries (Jagoda 2016). Reflecting on a collaborative research project working with a software company to develop an online computer game, Jagoda offers a fascinating set of theoretical and auto-ethnographic reflections on collaboration. Drawing on Castells, Jagoda argues that within a network society, collaboration becomes a key network practice that 'belongs as much to the ethical and political as to the organisational' (ibid, 207). He asks about the ethical dimensions of collaborative activity and points to the importance of 
understanding collaboration in a dual sense: as both 'complicity' and 'collectivity'. His focus is less on the structures that reify organisational forms than on the relationships that 'privilege provisional contact over corporate networking' (ibid, 208).

Acknowledging the dominant influence of participatory metaphors within contemporary politics, Jagoda questions the value of conceptualising academia as an 'autonomous' critical space outside of collaboration or participation. Inspired by deconstructive theory, and leaving behind more structuralist maps of disciplinary knowledge production, Jagoda questions classical (Marxist) models of refusal and resistance, and the assumption that one should organise in opposition to a dominant power. He instead argues for a 'participatory and reflexive' $(2016,207)$ approach to network working. Rather than conceptualising boundaries and structural barriers, Jagoda offers 'participation as a process of reflective entanglement that oscillates between possible involvements and transformations' (ibid, 208). 'Oscillation' conveys ambivalence, movement and insight, pointing to the glimpses of critical epistemological insights generated by a journey across internal disciplinary divides.

\section{Conclusion}

Doctoral collaborations with 'non-academic' organisations are a feature of many leading university-based research training programmes. The challenges that this presents for social science doctoral students and their supervisors reward close attention. Policy-makers expect academics to foster these collaborations, including placements/internships, partnerships and knowledge exchanges, recognising the diversity of places at which social knowledge now gets generated and the broad potential for the development of awareness and capacity. At the same time, policy debates about what needs to change in doctoral training have been dominated by what we have termed 'one-dimensional' conceptualisations, in which both 'problems' and 'solutions' are sometimes framed too simplistically to be helpful to those supporting social science doctorates.

Social science research is often necessarily constituted in such a way as to question the social arrangements, conceptual architecture, the taken-for-granted, the "what goes without saying' of public, private or third-sector organisations. Arguably, this questioning is integral, rather than optional, to the best independent-minded social science, and plays a vital role in any society claiming to have democratic values (Nussbaum 2012). The challenge is to preserve spaces for questioning and critique whilst making use of the learning opportunities presented by collaborative arrangements in the social sciences.

Neither normative critiques of the knowledge economy nor instrumentalist models of knowledge 'exchange' in themselves help students understand the dynamic, iterative and unpredictable work of collaboration and its critically creative potential to make or shape new disciplinary knowledge. Learning from the 'generative paradoxes' (Jagoda 2016) and 'reflective entanglements' (Bartunek and Rynes 2014) of collaborative working - especially different attitudes to time, knowledge and utility - needs to become integral to doctoral education. What we have termed a 'three-dimensional' approach to collaboration provides a basis for designing learning opportunities that can (and we would argue, should) be harnessed for the benefit of social science doctoral students.

Our approach has sought to account for and respect the various dimensions of social scientific collaborative endeavour. We have argued that embedding collaboration into doctoral training brings into epistemological relief the antagonistic interdependence of critical, 
professional, policy and public domains of disciplinary knowledge. It also supports students' analytical capabilities and versatility as social scientists. We have shown how Burawoy's vision for public sociology can be achieved through organisational collaborations and 'knowledge exchange', but this also requires critical reflexivity from students about their own positions and engagements within these collaborations. When and how these organisational entanglements and reflections occur requires serious and focused attention by those who fund, orchestrate and support doctoral education.

Open Access This article is distributed under the terms of the Creative Commons Attribution 4.0 International License (http://creativecommons.org/licenses/by/4.0/), which permits unrestricted use, distribution, and reproduction in any medium, provided you give appropriate credit to the original author(s) and the source, provide a link to the Creative Commons license, and indicate if changes were made.

\section{References}

Assbring, L., \& Nurr, C. (2017). What's in it for industry? A case study on collaborative doctoral education in Sweden. Industry and Higher Education, 31(3), 184-194.

Barnacle, R., \& Dall' Alba, G. (2011). Research degrees as professional education. Studies in Higher Education, 36(4), 459-470.

Bartunek, J. M., \& Rynes, S. L. (2014). Academics and practitioners are alike and unlike: the paradoxes of academic-practitioner relationships. Journal of Management, 40(5), 1181-1201.

Bell, D. (1973). The coming of post-industrial society: a venture in social forecasting. New York: Basic Books.

Bell, E., \& Read, C. (1998). On the CASE: advice for collaborative studentships. Swindon: ESRC.

Birch, K., \& Mykhenko, V. (2014). Lisbonizing versus financializing Europe? The Lisbon Agenda and the (un)making of the European knowledge-based economy. Environment and Planning. C, Government \& Policy, 32(1), 108-128.

Bloch, C., Graversen, E. K., \& Pedersen, H. S. (2015). Researcher mobility and sector career choices among doctorate holders. Research Evaluation, 24(2), 171-180.

Borrell-Damian, L., \& European University Association. (2009). Collaborative doctoral education: universityindustry partnerships for enhancing knowledge exchange. EUA: Brussels.

Borrell-Damian, L., Brown, T., \& Dearing, A. (2010). Collaborative doctoral education: university-industry partnerships for enhancing knowledge exchange. Higher Education Policy, 23(4), 493-514.

Brodin, E. M. (2016). Critical and creative thinking nexus: learning experiences of doctoral students. Studies in Higher Education, 41(6), 971-989.

Burawoy, M. (2005). For public sociology. American Sociological Review, 70(1), 4-28.

Calhoun, C. (2005). The promise of public sociology. The British Journal of Sociology, 56(3), 355-364.

Calhoun, C., \& Rhoten, D. (2010). Integrating the social sciences: theoretical knowledge, methodological tools, and practical applications. In R. Frodeman (Ed.), The Oxford handbook of interdisciplinarity. Oxford: OUP.

Chan, A. S., \& Fisher, D. (2008). The exchange university: the corporatisation of academic culture. Vancouver: UBC Press.

Chen, S., McAlpine, L., \& Amundsen, C. (2015). Postdoctoral positions as preparation for desired careers: a narrative approach to understanding postdoctoral experience. Higher Education Research and Development, 34(6), 1083-1096.

Demeritt, D. (2005). The promises of collaborative research. Environment and Planning A, 37(12), $2075-2082$.

Demeritt, D., \& Lees, L. (2005). Research relevance, 'knowledge transfer' and the geographies of CASE studentship collaboration. Area, 37(2), 127-137.

Enders, J. (2002). Serving many masters: The PhD on the labour market, the everlasting need of inequality, and the premature death of Humboldt. Higher Education, 44(3-4), 493-517.

Enders, J. (2005). Border crossings: research training, knowledge dissemination and the transformation of academic work. Higher Education, 49(1-2), 119-133.

Enders, J., \& de Weerdt, E. (2004). Science, training and career: changing modes of knowledge production and labour markets. Higher Education Policy, 17(2), 135-152.

Etmanski, B. (2019). The prospective shift away from academic career aspirations. Higher Education, 77(2), $343-358$. 
Etzkowitz, H., \& Leydesdorff, L. (1997). Universities in the global economy: a triple helix of university industry government relations. London: Cassell.

Etzkowitz, H., \& Leydesdorff, L. (1998). The endless transition: a "triple helix" of university-industrygovernment relations. Minerva, 36(3), 203-208.

Fatsis, L. (2014). Making sociology public: a critical analysis of an old idea and a recent debate. PhD, Sussex.

Gans, H. (2010). "Ethnography as Public Sociology." Qualitative Sociology 33(1): 97-104.

Gemme, B., \& Gingras, Y. (2008). The new production of researchers. In Chan \& Fisher (Eds.), The exchange university: the corporatisation of academic culture. Vancouver: UBC Press.

Gemme, B., \& Gingras, Y. (2012). Academic careers for graduate students: a strong attractor in a changed environment. Higher Education, 63(6), 667-683.

Gibbons, M., Limoges, C., Nowotny, H., Schwartzman, S., Scott, P., \& Trow, M. (1994). The new production of knowledge: the dynamics of science and research in contemporary societies. London: Sage.

Gu, J., Levin, J., \& Luo, Y. (2018). Reproducing "academic successors" or cultivating "versatile experts": influences of doctoral training on career expectations of Chinese PhD students. Higher Education, 76(3), $427-447$.

Hancock, S. (2019). A future in the knowledge economy? Analysing the career strategies of doctoral scientists through the principles of game theory. Higher Education, 78(1), 33-49.

Holmwood, J. (2007). Sociology as public discourse and professional practice: a critique of Michael Burawoy. Sociological Theory, 225(1), 46-66.

Jagoda, P. (2016). Network aesthetics. Chicago: Chicago University Press.

Jeffries, V. (2009). Handbook of public sociology. Lanham: Rowman \& Littlefield pub.

Kitigawa, F. (2014). Collaborative doctoral programmes: employer engagement, knowledge mediation and skills for innovation. Higher Education Quarterly, 68(3), 328-347.

Lam, A. (2010). From 'ivory tower traditionalists' to 'entrepreneurial scientists'?: academic scientists in Fuzzy university-industry boundaries. Social Studies of Science, 40(2), 307-340.

Lukes, S. (1974). Power : a radical view. Basingstoke: Macmillan.

Macfarlane, B. (2017). The paradox of collaboration: a moral continuum. Higher Education Research and Development, 36(3), 472-485.

McAlpine, L., \& Amundsen, C. (2017). Identity-trajectories of early career researchers:unpacking the post-PhD experience. London: Palgrave Macmillan.

McAlpine, L., \& Amundsen, C. (2019). Post-PhD career trajectories: intentions, decision-making and life aspirations. Heidelberg: Springer.

Mills, C. W. (1959). The sociological imagination. London: OUP.

Nichols, L. T. (2007). Public sociology : the contemporary debate. New Brunswick: Transaction Publishers.

Nussbaum, M. C. (2012). Not for profit : Why democracy needs the humanities. Princeton: Princeton University Press.

Nyden, P. W., Hossfeld, L. H., \& Nyden, G. E. (2012). Public sociology : Research, action, and change. Los Angeles: SAGE Pine Forge Press.

Reischauer, G. (2018). Industry 4.0 as policy-driven discourse to institutionalize innovation systems in manufacturing. Technological Forecasting and Social Change, 132, 26-33.

Riessman, C. K. (2008). Narrative methods for the human sciences. Los Angeles ; London: Sage Publications.

Salminen-Karlsson, M., \& Wallgren, L. (2008). The interaction of academic and industrial supervisors in graduate education: an investigation of industrial research schools. Higher Education, 56(1), 77-93.

Shinn, T. (2002). The triple helix and new production of knowledge: prepackaged thinking on science and technology. Social Studies of Science, 32(4), 599-614.

Stacey, J. (2007). If I were the goddess of sociological things. In D. Clawson (Ed.), Public sociology : fifteen eminent sociologists debate politics and the profession in the twenty-first century. Berkeley: University of California Press.

Slaughter, S., \& Rhoades, G. (2004). Academic capitalism and the new economy: Markets, State and Higher Education. Baltimore, John Hopkins Press.

Slaughter, S., T. Campbell, M. Holleman and E. Morgan (2002). The "traffic" in graduate students: Graduate students as tokens of exchange between academe and industry. Science Technology \& Human Values 27(2): $282-312$.

Thune, T. (2009). Doctoral students on the university-industry interface: a review of the literature. Higher Education, 58, 637-651.

Thune, T. (2010). The training of "triple helix workers"? Doctoral students in university-industry-government collaborations. Minerva, 48(4), 463-483.

Treasury, HM. (2003). The Lambert review of business-university collaboration final report. London, HMSO

Veblen, T. (1957). The higher learning in America : a memorandum on the conduct of universities by business men. New York: B. W. Huebsch. 
Waddock, S. (2017). Connecting — making social science matter: the collaborative and boundary-spanning work of intellectual shamans. In Bartunek \& McKenzie (Eds.), Academic-Practitioner Relationships. London: Routledge.

Wilson, T. (2012) A Review of Business-University Collaboration. BIS/12/610. Department of Business, innovation and skills, London. https://www.gov.uk/government/publications/business-universitycollaboration-the-wilson-review

Wright, S. (2016). The imaginators of English university reform. In Slaughter \& Taylor (Eds.), Higher education, stratification, and workforce development: competitive advantage in Europe, the US, and Canada (Vol. 45, pp. 127-149). Cham: Springer Higher Education Dynamics.

Publisher's note Springer Nature remains neutral with regard to jurisdictional claims in published maps and institutional affiliations. 